\title{
Fate of graft cells: what should be clarified for development of mesenchymal stem cell therapy for ischemic stroke?
}

\section{Yuka Ikegame ${ }^{1,2,3}$ *, Kentaro Yamashita ${ }^{4,5}$, Shigeru Nakashima ${ }^{3}$, Yuichi Nomura ${ }^{1}$, Shingo Yonezawa ${ }^{1}$, Yoshitaka Asano ${ }^{1,2}$, Jun Shinoda ${ }^{1,2}$, Hideaki Hara ${ }^{6}$ and Toru Iwama ${ }^{4}$}

${ }^{1}$ Department of Neurosurgery, Chubu Medical Center for Prolonged Traumatic Brain Dysfunction, Gifu, Japan

2 Department of Clinical Brain Sciences, Gifu University Graduate School of Medicine, Gifu, Japan

${ }^{3}$ Department of Cell Signaling, Gifu University Graduate School of Medicine, Gifu, Japan

${ }^{4}$ Department of Neurosurgery, Gifu University Graduate School of Medicine, Gifu, Japan

${ }^{5}$ Department of Neurosurgery, Murakami Memorial Hospital, Asahi University, Gifu, Japan

${ }^{6}$ Department of Biofunctional Evaluation, Molecular Pharmacology, Gifu Pharmaceutical University, Gifu, Japan

\section{Edited by:}

Thorsten Doeppner, University of Duisburg-Essen, Germany

\section{Reviewed by:}

Sebastian Illes, Paracelsus Medical University, Austria

Marcel Dihné, University of Tübingen, Germany

\section{*Correspondence:}

Yuka Ikegame, Department of Neurosurgery, Chubu Medical Center for Prolonged Traumatic Brain Dysfunction and Department of Clinical Brain Sciences, Gifu University Graduate School of Medicine, 630 Shimo-kobi, Minokamo, Gifu 505-0034, Japan; Department of Cell Signaling, Gifu University Graduate School of Medicine, 1-1 Yanagido, Gifu, Gifu 501-1194, Japan

e-mail: ikegame-nsu@umin.ac.jp
Mesenchymal stem cells (MSCs) are believed to be promising for cell administration therapy after ischemic stroke. Because of their advantageous characteristics, such as ability of differentiation into neurovascular lineages, avoidance of immunological problems, and abundance of graft cells in mesodermal tissues, studies regarding MSC therapy have increased recently. However, several controversies are yet to be resolved before a worldwide consensus regarding a standard protocol is obtained. In particular, the neuroprotective effects, the rate of cell migration to the lesion, and differentiation direction differ depending on preclinical observations. Analyses of these differences and application of recent developments in stem cell biology or engineering in imaging modality may contribute to identification of criteria for optimal stem cell therapy in which reliable protocols, which control cell quality and include safe administration procedures, are defined for each recovery phase after cerebral ischemia. In this mini review, we examine controversies regarding the fate of grafts and the prospects for advanced therapy that could be obtained through recent developments in stem cell research as direct conversion to neural cells.

Keywords: mesenchymal stem cell, ischemic stroke, stem cell therapy, translational research, neurovascular unit

\section{DEVELOPMENT OF MESENCHYMAL STEM CELL THERAPY STUDY FOR ISCHEMIC STROKE}

Ischemic stroke is a common central nervous system (CNS) disease. Despite continuous development in treatments, stroke is still a major cause of death or disability, and therefore, more effective therapies are required. In 1990s, clinical trials neuroprotective agents targeted single mechanism, i.e., glutamate-induced neurotoxicity revealed to become failure (Hoyte et al., 2004). In the lesion insulted by brain ischemia, multiple pathogenic mechanisms are activated. As the failures in the early neuroprotective drug development showed (Degraba and Pettigrew, 2000), a genuine effective therapy would be required to solve the pleiotropic pathology (Teng et al., 2008; Guo and Lo, 2009).

Another concept to treat lost function by ischemia is to supply cells or tissue for replacement of the damaged brain tissue. In the early days of stem cell research, stem cells were expected as a source of tissue regeneration. Since the publication of the earliest reports of attempted administration of embryonic or neonatal neural stem cells for regeneration of the CNS in the early 1990s (Renfranz et al., 1991; Snyder et al., 1992), diverse cell types have been investigated to identify an ideal cell line to generate tissue grafts for CNS. Candidate cells can be categorized into embryonic, fetal, neonatal, or adult by maturation of each origin tissue. When categorized by a stage of differentiation, the examined cells can be sourced from pluripotent cells (embryonic stem cells or induced pluripotent cells), ectodermal lineage (neural stem cells, olfactory neuroepithelial stem cells, or NT2 cell line derived from neuroteratocarcinoma), mesodermal lineage [mesenchymal stem cells (MSCs), CD34+ cells, endothelial progenitor cells, hematopoietic stem cells, or bone marrow mononuclear/stromal cells]. As discussed in published reviews on stem cell therapies (Locatelli et al., 2009; Bhasin et al., 2013; Kalladka and Muir, 2014), neural stem cells, and mesodermal lineage listed above have already been applied for ischemic stroke in clinical settings from subacute phase to chronic phase.

In this mini review, the advantages of MSCs, as a source for stem cell therapy, are summarized. Furthermore, controversial points in preclinical experimental studies and the developing field of MSC therapy resulting from the recent evolution in stem cell biology are discussed by focusing on the biological features of mesenchymal stem cells (MSCs).

Among stem cell therapies, the greatest numbers of clinical trial for MSC have been conducted (Rosado-De-Castro et al., 2013a), thus MSC therapy can be the most practical stroke treatments in cell-based therapies (Eckert et al., 2013). More than 30 years after when Friedenstein et al. (1966) isolated osteogenic cell population 
from bone marrow, MSCs have been identified in bone marrow (Pittenger et al., 1999), adipose tissue (Zuk et al., 2002), umbilical cord (Erices et al., 2000), peripheral blood (Ukai et al., 2007), dental pulp (Gronthos et al., 2000), and a wide range of mesodermal tissues including perivascular site in brain (Kang et al., 2010; Paul etal., 2012). The criteria for identifying MSCs as proposed by the Mesenchymal and Tissue Stem Cell Committee of the International Society for Cellular Therapy are (1) plastic adherence of isolated cells in culture; (2) in cell surface marker analysis, $>95 \%$ of the culture positively expressing the cell surface markers CD105, CD73, and CD90, while being negative for CD34, CD45, CD14, or CD11b, CD79a, or CD19, and human leukocyte antigen-DR; and (3) in vitro differentiation into three mesodermal cell types, namely osteoblasts, adipocytes, and chondroblasts (Dominici et al., 2006). Moreover, the characteristics of MSC present advantages. MSC have been shown their multipotency that is beneficial to differentiate into multiple lineages to repair neurovascular unit or neural network; they could demonstrate multiphasic actions to modify endogenous repairing process including reprogramming, harmful immune response, or chemical reactions via secretion abilities; they are easier to prepare for grafting due to their accessible cell source and proliferation potential for rapid cell expansion. (Doeppner and Hermann, 2010; Grande et al., 2013; Wan et al., 2013)

The first series of successful experiments for MSCs for the treatment of ischemic stroke was reported by Chopp's group (Chen et al., 2000; Li et al., 2000; Zhang et al., 2000). They have examined multiple protocols for bone marrow stromal-derived stem cells (BMSCs) such as administration route (intracerebral, transventricular, intra-arterial, transvenous), timing, or dose, as well as have analyzed mechanisms of functional recovery focused on restore or remodeling functional connectivity in neural circuits/tract. Subsequently, details required for the establishment of safe and effective therapy protocols (Borlongan, 2009; The STEPS Participants, 2009; Savitz etal., 2011) have been analyzed by a number of investigators. Most results in the preclinical studies have indicated that MSC administration is beneficial. In this context, clinical trials employing systemic administration via peripheral veins were initiated more recently (Lee et al., 2010; Honmou et al., 2011). So far, these trials have not demonstrated severe adverse results (Lalu et al., 2012), even during observation periods lasting longer than a few years, despite the prediction of risks, such as embolization (Ge et al., 2014; Yavagal et al., 2014), infection, and tumorigenesis (Coussens et al., 2000; Li et al., 2007), in experimental studies.

\section{CONTROVERSIES IN PRECLINICAL STAGE}

Overall, accumulated findings have indicated that MSC therapy is reliable for stroke treatment. However, several points must be clarified for achievement of consensus as a reliable protocol. As shown in Table 1, the conditions of some preclinical studies resulted in differing outcomes because of graft cell detection in the lesion, infarct volume reduction, functional recovery, marker expression (neuronal, glial, or vascular: direction of differentiation), and the type of MSCs considered to have more therapeutic effects, particularly BMSCs and adipose tissue-derived stem cells (ASCs).

\section{MIGRATION TO THE LESION}

A major discrepancy in the results of preclinical studies is whether graft cells have the ability to migrate to a cerebral lesion, although mechanisms of MSC transmigration across the blood-brain barrier (BBB) have been analyzed (Liu et al., 2013). The accumulation of graft cells in the lesion is expected to directly enhance neuroprotection and cell replacement in infarcted tissue. A comparison of different administration routes revealed that transarterial delivery was more successful in order to detect graft cells in the brain than transvenous delivery, although several studies reported a decrease in the number of detected cells in the later phase (Ishizaka et al., 2013; Mitkari et al., 2013). The transvenous route induced fewer side effects than intra-arterial infusion; however, physiologically, graft cells must pass through several traps, such as the lung and BBB. Although, the BBB can be disrupted by ischemic insult around the damaged areas, MSCs may have the basic ability to transmigrate the BBB as immune cells in response to homing signals to the lesion (Liu et al., 2013). Nonetheless, there are certainly successful examples demonstrating the integration of graft cells in the peri-infarct area even after transvenous infusion from a peripheral vessel (Table 1).

Classically, immunohistological analysis is a standard method to detect MSC migration, but recent imaging techniques, such as magnetic resonance imaging (MRI) with magnetic cell labeling (Detante et al., 2012; Canazza et al., 2013) and nuclear imaging using ${ }^{99 \mathrm{~m}}$ Tc-labeled graft (Detante et al., 2009; Vasconcelos-DosSantos et al., 2012), have been proposed to reveal the distribution of MSCs. Subsequently, a phase I clinical trial employing ${ }^{99 \mathrm{~m}} \mathrm{Tc}-$ single photon emission computed tomography (SPECT) for assessment of biodistribution of the labeled grafts in subacute patients have safely conducted (Rosado-De-Castro et al., 2013b). The findings of these recent analytical methods may resolve the question of accurate distribution of graft cells.

\section{FUNCTIONAL RECOVERY}

Many preclinical studies have also reported differences in infarct volume reduction and functional recovery (Hao et al., 2014). Assessment methods of functional recovery vary, although there certainly are popular tests in animal studies, such as the treadmill test or Roger's test. Therefore, differences in functional assessment may simply be based on differences in the employed assessment methods. On the other hand, it is more difficult to elucidate discrepancies in infarct volume reduction. In vivo studies with rodents have been conducted to investigate the changes in infarct volume reduction by direct measurement of the brain tissue after decapitation. Regarding clinical applications, non-invasive methods, such as MRI, may be beneficial to translate the findings of in vivo studies to clinical settings. Although the availability of mechanical devices varies among laboratories, the development of alternative clinical methods is recommended for future in vivo experiments.

Another problem is whether MSCs isolated from different tissues also differ. MSCs are obtained from diverse mesodermal tissues, i.e., bone marrow, adipose tissue, dental pulp, or cord blood. MSCs from different sources show different characteristics in vitro (Kern et al., 2006; Hsiao et al., 2012). Therefore, comparative study for different cell sources as conducted by 


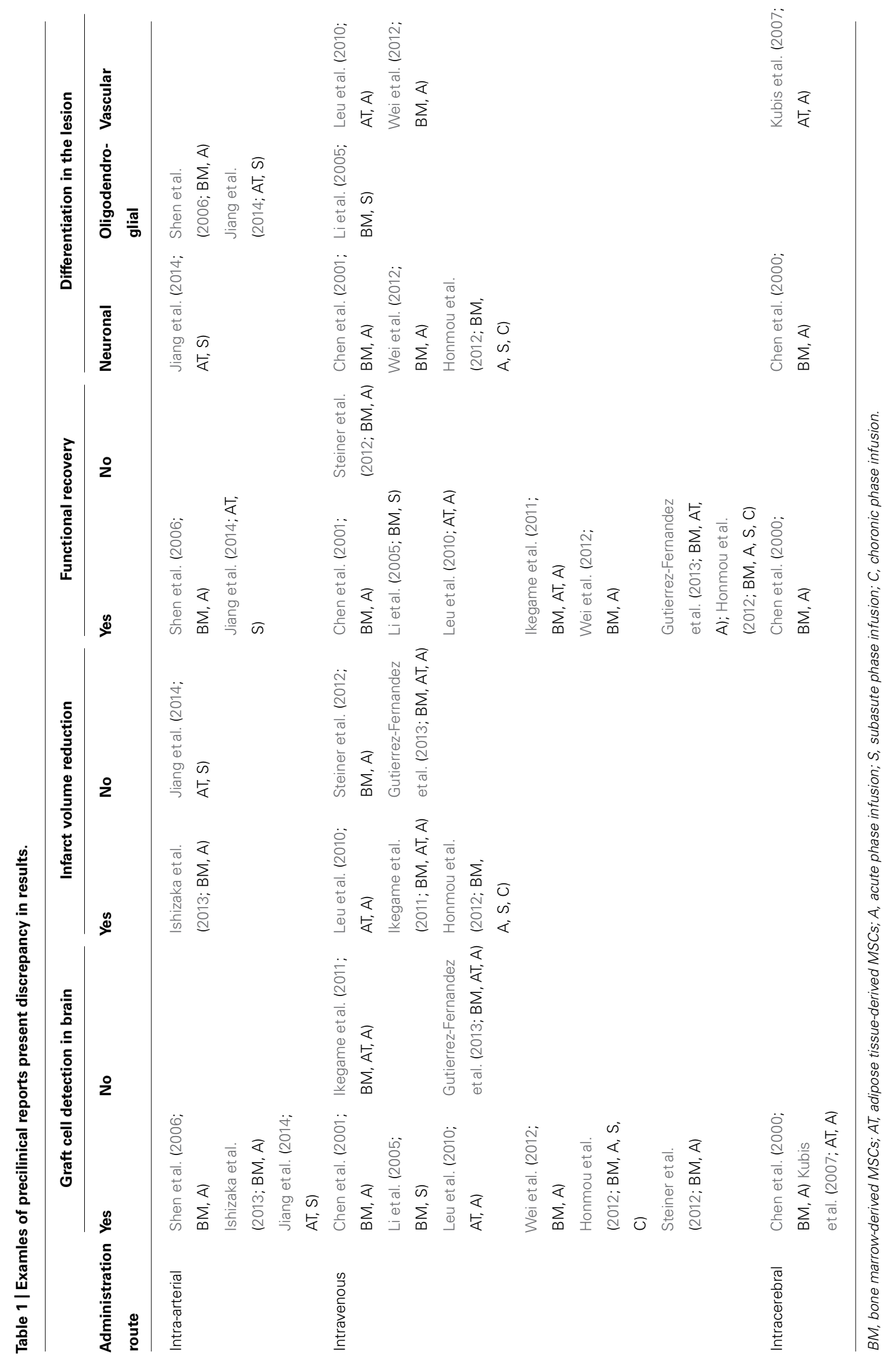


Gutierrez-Fernandez's group is important, however, the therapeutic effects in similar experimental ischemic stroke models also differ in transvenous administration studies (Ikegame et al., 2011; Steiner et al., 2012; Gutierrez-Fernandez et al., 2013) compared to intra-arterial administration studies that have shown graft cells in the lesion. (Table 1)

On the other hand, nuclear imaging is another available method to assess the therapeutic effectiveness. Diffusion and perfusionweighted imaging provide information of blood supply in the brain (Canazza etal., 2013). Furthermore, functional MRI is employed by experimental studies in rodents, which unable to assess functional recovery (Suzuki et al., 2013) and even neural network by analyses of resting state functional MRI (Canazza et al., 2013). The neural integrity has been investigated by ${ }^{123} \mathrm{I}-$ Iomazenil SPECT (Saito etal., 2013). A ${ }^{18}$ F-FDG positron emission tomography study have measured glucose metabolism after MSC therapy in rats for cerebral ischemia (Miyamoto et al., 2013). For assessment of functional recovery, these methods from more biofunctional aspect would be practical in addition to observations of behavioral change.

\section{DIRECTION OF DIFFERENTIATION}

The direction of differentiation also remains controversial for in vivo experimental studies. Although MSCs are derived from mesenchymal tissue, they exhibit multipotency and transdifferentiation into ectodermal lineages, including neural cells, both in vitro and in vivo (Zuk, 2013). Previous in vitro immunochemistry studies have demonstrated the ability of MSCs to differentiate into cell types that comprise the neurovascular unit, including neurons, astrocytes (Wislet-Gendebien et al., 2004), and endothelial cells (Hess et al., 2002; Planat-Benard et al., 2004). Moreover, possible differentiation abilities toward oligodendrocyte lineage (NG2-positive cells; Shen et al., 2006), specific types of neurons, such as glutamatergic neurons (Yu et al., 2014), and smooth muscle cells of vessels (Kubis et al., 2007) have been demonstrated. In vivo studies have reported that graft cells detected in the lesion result from neuronal or glial differentiation (Guzman et al., 2008). However, one study demonstrated the vascular fate rather than differentiation to neural lineages (Kubis et al., 2007).

To ensure the practical differentiation, in addition to these morphological, immunohistochemical, or genetic assessments, cells should be further examined. With respect to neural differentiation, neurotransmitter responsiveness or electrophysiological recording is required to examine their function as a neuron (Yang et al., 2011). Moreover, when MSCs are employed, absence of cell fusion also should be excluded. Though the MSC's rate of spontaneous cell fusion is only $2-11$ clones per million cells (Terada et al., 2002), and the mechanism may also participate in the tissue repair, nonetheless, biologically it should be distinguished from differentiation. BMSC and ASC are observed the neural differentiation that can show neural function in earlier studies. First, Ashjian et al. (2003) recorded $\mathrm{K}^{+}$current on neuronal cells induced from ASC. Cho et al. (2005) reported synaptic transmission, and Wislet-Gendebien et al. (2005) showed action potential of the neuron-like cells differentiated from BMSC.

\section{AUTOLOGOUS OR ALLOGENIC?}

With the exception of the acute phase after ischemic insult, both allogenic and autologous grafting of MSCs can be prepared. Although the efficacy of technologies has improved, besides the advantage of MSCs in immunomodulation, theoretically allogenic grafts cannot ameliorate all concerns regarding transinfection or immunological side effects. Autologous grafts can overcome the problems related to allogenic cells. Nonetheless, at the present stage, other than obtaining the major MSCs, the use of both BMSCs and ASCs requires invasive procedures. Bone marrow aspiration and harvesting of adipose tissue are considered safe and established techniques; however, because ischemic stroke patients usually take antiplatelet or anticoagulant agents, and in some case, the patient may be intolerant to other conditions, further less invasive methods, such as the use of peripheral blood, present alternative sources of cells. As mentioned in the previous section, each type of MSCs from different cell sources tend to exhibit original traits or abilities, although they meet the criteria of MSCs. Knowledge regarding defined factors/conditions for MSC-fate regulation could enable the preparation of homogenous MSCs, even from peripheral blood (Meng et al., 2013).

Autologous grafts may have an additional advantage over allogenic grafts. In preclinical observations, MSCs reportedly developed function following contact with a conditioned media (Egashira etal., 2013), serum (Honmou etal., 2011), or cerebrospinal fluid from patients (Orito et al., 2010), which is reflected in the biological responses to invasive stimulation. It is possible that MSCs may achieve proper function in reaction to insults (Kurozumi et al., 2005; Xin et al., 2013). Therefore, graft cells harvested from ischemic stroke patients may gain more favorable function than allogenic grafts from those who are not affected by ischemic insults. Strikingly, the first nonrandomized clinical trial for a protocol with autologous BMSCs and serum has been shown to be safe and effective (Bang et al., 2005; Lee et al., 2010; Honmou et al., 2011). A 5-year randomized trial also began in 2012, which will provide further information regarding autologous stem cell therapy (Kim et al., 2013).

\section{POSSIBILITY OF ADVANCED MSC THERAPIES AS A SOLUTION OF QUESTIONS MSC MODIFICATION AND IDENTIFICATION BY DEFINED FACTORS RELATED TO CELL FATE REGULATION}

From a pharmacological viewpoint, the actions of agents should be confirmed after administration. If MSCs are regarded as a type of biological drug, then differences in differentiation ability should be better clarified.

Emerging induced pluripotent stem cells (iPSC) studies have shown promising benefits in the field of regenerative medicine that could have at least two major impacts on MSC studies. These findings may be useful to settle the controversies listed above, particularly those regarding the direction of differentiation of graft cells in the host and differences in the characteristics of MSCs originating from the cell source.

First, the appearance of iPSCs indicates the potential of multipotency in somatic cells (Takahashi and Yamanaka, 2006), which is supported by observations of differentiation into either neural or endothelial cells in MSCs. Although many reports 
Table 2 | Suggested factors related to cell fate regulation for direct conversion.

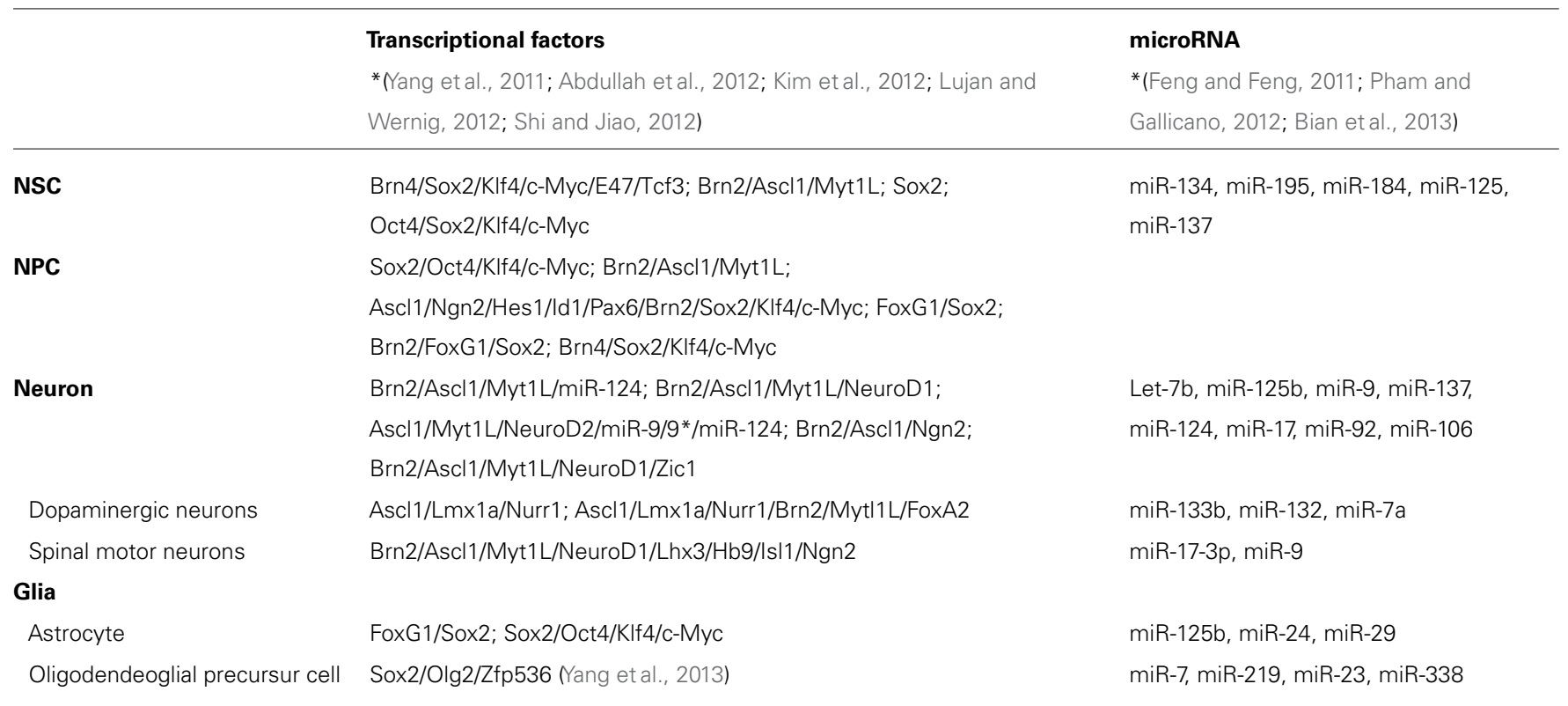

*Review articles.

have demonstrated the ability MSCs of mesodermal origin to differentiate into other type of germ cells of ectodermal lineages (neural cells) and endodermal lineages (insulin-producing cells), which could indicate multipotency, the defined conditions for MSCs to differentiate into neural cells remain uncertain. In the infancy of stem cell research, cell fusion and contamination of neural crest cells were suggested as the mechanism of a graft cell to express neural markers in the host tissue after cell administration (Wrage et al., 2008; Maltman et al., 2011). If the postulates reveal to be the main mechanism, neural marker expression can't be called neural differentiation, which unable MSC to be called "stem cell." Therefore, until recently, the term "MSC" containing the term "stem cell" had its pros and cons, and thus, MSCs were called stromal cells. However, successful reprogramming of skin fibroblasts to the multipotent state has provided more information to support the multipotency of MSCs.

Second, induction techniques may contribute to further elucidate the quality control mechanisms for the use of MSCs. Protocols for chemical induction to neuron or glia had been developed recently (Safford and Rice, 2005; Franco Lambert et al., 2009; Yu et al., 2011). Following the publication of methods to harness and propagate iPSCs, other methods related to direct conversion from fibroblasts to neuronal cells by defined transcription factors have been reported (Vierbuchen et al., 2010; Yang et al., 2013). The neural lineage is composed of induced neuronal (iN) cells, induced neural progenitor cells (iNPCs), and induced NSCs (iNSCs; Yang et al., 2011; Abdullah et al., 2012; Corti et al., 2012; Shi and Jiao, 2012). Moreover, iPSC-derived MSCs (iPSC-MSCs) were identified (Jung et al., 2012). There are multiple pathways for neural induction. As listed in the Table 2, in addition to defined transcriptional factors for direct conversion, microRNA (Feng and Feng, 2011; Pham and Gallicano, 2012; Bian et al.,
2013) or other epigenetic factors (Namihira and Nakashima, 2011) can contribute to differentiation. The definitive conditions to propagate/identify iN cells, iNSCs, iNPCs, or iPSC-MSCs may be useful to propose a standard protocol for the required type of MSCs.

\section{ORGANOGENESIS FOR TISSUE REPLACEMENT}

Lancaster et al.'s (2013) team developed a three-dimensional brain tissue from iPSCs by the floating culture method. To obtain functional recovery in vivo, several groups have shown that tissue regeneration or replacement of damaged tissue with ex vivo materials is not always necessary (Table 1). Particularly in the brain tissue, repair of the neural circuitry is required to improve function. Nonetheless, tissue engineering using scaffolds (Mahmood et al., 2013) or novel organogenesis methods present possible transplantation treatments to recover neurological deficits.

\section{CONCLUSION}

Since the first report of MSC (Pittenger et al., 1999), investigators have revealed favorable cell characteristics for cell therapies and have shown evidence for feasible stem cell therapy using MSCs in order to achieve safe applications in clinical settings. However, there are limited methods to ensure reliable treatment. Nevertheless, further studies combined with developments in other biological and/or engineering fields may solve these present problems, and establish an ideal stem cell therapy beyond categorization of MSCs.

\section{ACKNOWLEDGMENT}

This work was supported in part by Japan Society for the Promotion of Science (JSPS KAKENHI Grant Number 24700824) to Yuka Ikegame. 


\section{REFERENCES}

Abdullah, A. I., Pollock, A., and Sun, T. (2012). The path from skin to brain: generation of functional neurons from fibroblasts. Mol. Neurobiol. 45, 586-595. doi: 10.1007/s12035-012-8277-6

Ashjian, P. H., Elbarbary, A. S., Edmonds, B., Deugarte, D., Zhu, M., Zuk, P. A., et al. (2003). In vitro differentiation of human processed lipoaspirate cells into early neural progenitors. Plast. Reconstr. Surg. 111, 1922-1931. doi: 10.1097/01.PRS.0000055043.62589.05

Bang, O. Y., Lee, J. S., Lee, P. H., and Lee, G. (2005). Autologous mesenchymal stem cell transplantation in stroke patients. Ann. Neurol. 57, 874-882. doi: 10.1002/ana.20501

Bhasin, A., Srivastava, M. V., Mohanty, S., Bhatia, R., Kumaran, S. S., and Bose, S. (2013). Stem cell therapy: a clinical trial of stroke. Clin. Neurol. Neurosurg. 115, 1003-1008. doi: 10.1016/j.clineuro.2012.10.015

Bian, S., Xu, T. L., and Sun, T. (2013). Tuning the cell fate of neurons and glia by microRNAs. Curr. Opin. Neurobiol. 23, 928-934. doi: 10.1016/j.conb.2013. 08.002

Borlongan, C. V. (2009). Cell therapy for stroke: remaining issues to address before embarking on clinical trials. Stroke 40, S146-S148. doi: 10.1161/STROKEAHA.108.533091

Canazza, A., Minati, L., Boffano, C., Parati, E., and Binks, S. (2013). Experimental models of brain ischemia: a review of techniques, magnetic resonance imaging, and investigational cell-based therapies. Front. Neurol. 5:19. doi: 10.3389/fneur.2014.00019

Chen, J., Li, Y., and Chopp, M. (2000). Intracerebral transplantation of bone marrow with BDNF after MCAo in rat. Neuropharmacology 39, 711-716. doi: 10.1016/S0028-3908(00)00006-X

Chen, J., Li, Y., Wang, L., Lu, M., Zhang, X., and Chopp, M. (2001). Therapeutic benefit of intracerebral transplantation of bone marrow stromal cells after cerebral ischemia in rats. J. Neurol. Sci. 189, 49-57. doi: 10.1002/jnr.10691

Cho, K. J., Trzaska, K. A., Greco, S. J., Mcardle, J., Wang, F. S., Ye, J. H., etal. (2005). Neurons derived from human mesenchymal stem cells show synaptic transmission and can be induced to produce the neurotransmitter substance P by interleukin-1 alpha. Stem Cells 23, 383-391. doi: 10.1634/stemcells. 2004-0251

Corti, S., Nizzardo, M., Simone, C., Falcone, M., Donadoni, C., Salani, S., et al. (2012). Direct reprogramming of human astrocytes into neural stem cells and neurons. Exp. Cell Res. 318, 1528-1541. doi: 10.1016/j.yexcr.2012.02.040

Coussens, L. M., Tinkle, C. L., Hanahan, D., and Werb, Z. (2000). MMP-9 supplied by bone marrow-derived cells contributes to skin carcinogenesis. Cell 103, 481-490. doi: 10.1016/s0092-8674(00)00139-2

Degraba, T. J., and Pettigrew, L. C. (2000). Why do neuroprotective drugs work in animals but not humans? Neurol. Clin. 18, 475-493. doi: 10.1016/S00928674(00)00139-2

Detante, O., Moisan, A., Dimastromatteo, J., Richard, M. J., Riou, L., Grillon, E., et al. (2009). Intravenous administration of 99mTc-HMPAO-labeled human mesenchymal stem cells after stroke: in vivo imaging and biodistribution. Cell Transplant. 18, 1369-1379. doi: 10.3727/096368909X474230

Detante, O., Valable, S., De Fraipont, F., Grillon, E., Barbier, E. L., Moisan, A., et al. (2012). Magnetic resonance imaging and fluorescence labeling of clinicalgrade mesenchymal stem cells without impacting their phenotype: study in a rat model of stroke. Stem Cells Transl. Med. 1, 333-341. doi: 10.5966/sctm. 2011-0043

Doeppner, T. R., and Hermann, D. M. (2010). Mesenchymal stem cells in the treatment of ischemic stroke: progress and possibilities. Stem Cells Cloning 3, 157-163. doi: 10.2147/SCCAA.S7820

Dominici, M., Le Blanc, K., Mueller, I., Slaper-Cortenbach, I., Marini, F., Krause, D., et al. (2006). Minimal criteria for defining multipotent mesenchymal stromal cells. The International Society for Cellular Therapy position statement. Cytotherapy 8, 315-317. doi: 10.1080/14653240600855905

Eckert, M. A., Vu, Q., Xie, K., Yu, J., Liao, W., Cramer, S. C., et al. (2013). Evidence for high translational potential of mesenchymal stromal cell therapy to improve recovery from ischemic stroke. J. Cereb. Blood Flow Metab. 33, 1322-1334. doi: 10.1038/jcbfm.2013.91

Egashira, Y., Suzuki, Y., Azuma, Y., Takagi, T., Mishiro, K., Sugitani, S., et al. (2013). The growth factor progranulin attenuates neuronal injury induced by cerebral ischemia-reperfusion through the suppression of neutrophil recruitment. J. Neuroinflammation 10, 105. doi: 10.1186/1742-2094-10-105
Erices, A., Conget, P., and Minguell, J. J. (2000). Mesenchymal progenitor cells in human umbilical cord blood. Br. J. Haematol. 109, 235-242. doi: 10.1046/j.13652141.2000.01986.x

Feng, W., and Feng, Y. (2011). MicroRNAs in neural cell development and brain diseases. Sci. China Life Sci. 54, 1103-1112. doi: 10.1007/s11427-0114249-8

Franco Lambert, A. P., Fraga Zandonai, A., Bonatto, D., Cantarelli Machado, D., and Pegas Henriques, J. A. (2009). Differentiation of human adipose-derived adult stem cells into neuronal tissue: does it work? Differentiation 77, 221-228. doi: 10.1016/j.diff.2008.10.016

Friedenstein, A. J., Piatetzky-Shapiro, I. I., and Petrakova, K. V. (1966). Osteogenesis in transplants of bone marrow cells. J. Embryol. Exp. Morphol. 16, 381-390.

Ge, J., Guo, L., Wang, S., Zhang, Y., Cai, T., Zhao, R. C., et al. (2014). The size of mesenchymal stem cells is a significant cause of vascular obstructions and stroke. Stem Cell Rev. 10, 295-303. doi: 10.1007/s12015-013-9492-x

Grande, A., Sumiyoshi, K., Lopez-Juarez, A., Howard, J., Sakthivel, B., Aronow, B., et al. (2013). Environmental impact on direct neuronal reprogramming in vivo in the adult brain. Nat. Commun. 4, 2373. doi: 10.1038/ncomms3373

Gronthos, S., Mankani, M., Brahim, J., Robey, P. G., and Shi, S. (2000). Postnatal human dental pulp stem cells (DPSCs) in vitro and in vivo. Proc. Natl. Acad. Sci. U.S.A. 97, 13625-13630. doi: 10.1073/pnas.240309797

Guo, S., and Lo, E. H. (2009). Dysfunctional cell-cell signaling in the neurovascular unit as a paradigm for central nervous system disease. Stroke 40, S4-S7. doi: 10.1161/STROKEAHA.108.534388

Gutierrez-Fernandez, M., Rodriguez-Frutos, B., Ramos-Cejudo, J., Teresa VallejoCremades, M., Fuentes, B., Cerdan, S., et al. (2013). Effects of intravenous administration of allogenic bone marrow- and adipose tissue-derived mesenchymal stem cells on functional recovery and brain repair markers in experimental ischemic stroke. Stem Cell Res. Ther. 4, 11. doi: 10.1186/ scrt159

Guzman, R., Choi, R., Gera, A., De Los Angeles, A., Andres, R. H., and Steinberg, G. K. (2008). Intravascular cell replacement therapy for stroke. Neurosurg. Focus 24, E15. doi: 10.3171/FOC/2008/24/3-4/E14

Hao, L., Zou, Z., Tian, H., Zhang, Y., Zhou, H., and Liu, L. (2014). Stem cell-based therapies for ischemic stroke. Biomed. Res. Int. 2014, 468748. doi: $10.1155 / 2014 / 468748$

Hess, D. C., Hill, W. D., Martin-Studdard, A., Carroll, J., Brailer, J., and Carothers, J. (2002). Bone marrow as a source of endothelial cells and NeuN-expressing cells after stroke. Stroke 33, 1362-1368. doi: 10.1161/01.STR.0000014925. 09415.C3

Honmou, O., Houkin, K., Matsunaga, T., Niitsu, Y., Ishiai, S., Onodera, R., et al. (2011). Intravenous administration of auto serum-expanded autologous mesenchymal stem cells in stroke. Brain 134, 1790-1807. doi: 10.1093/brain/awr063

Honmou, O., Onodera, R., Sasaki, M., Waxman, S. G., and Kocsis, J. D. (2012). Mesenchymal stem cells: therapeutic outlook for stroke. Trends Mol. Med. 18, 292-297. doi: 10.1016/j.molmed.2012.02.003

Hoyte, L., Barber, P. A., Buchan, A. M., and Hill, M. D. (2004). The rise and fall of NMDA antagonists for ischemic stroke. Curr. Mol. Med. 4, 131-136. doi: $10.2174 / 1566524043479248$

Hsiao, S. T., Asgari, A., Lokmic, Z., Sinclair, R., Dusting, G. J., Lim, S. Y., et al. (2012). Comparative analysis of paracrine factor expression in human adult mesenchymal stem cells derived from bone marrow, adipose, and dermal tissue. Stem Cells Dev. 21, 2189-2203. doi: 10.1089/scd.2011.0674

Ikegame, Y., Yamashita, K., Hayashi, S., Mizuno, H., Tawada, M., You, F., et al. (2011). Comparison of mesenchymal stem cells from adipose tissue and bone marrow for ischemic stroke therapy. Cytotherapy 13, 675-685. doi: $10.3109 / 14653249.2010 .549122$

Ishizaka, S., Horie, N., Satoh, K., Fukuda, Y., Nishida, N., and Nagata, I. (2013). Intra-arterial cell transplantation provides timing-dependent cell distribution and functional recovery after stroke. Stroke 44, 720-726. doi: 10.1161/STROKEAHA.112.677328

Jiang, W., Liang, G., Li, X., Li, Z., Gao, X., Feng, S., et al. (2014). Intracarotid transplantation of autologous adipose-derived mesenchymal stem cells significantly improves neurological deficits in rats after MCAo. J. Mater. Sci. Mater. Med. 25, 1357-1366. doi: 10.1007/s10856-014-5157-9

Jung, Y., Bauer, G., and Nolta, J. A. (2012). Concise review: induced pluripotent stem cell-derived mesenchymal stem cells: progress toward safe clinical products. Stem Cells 30, 42-47. doi: 10.1002/stem.727 
Kalladka, D., and Muir, K. W. (2014). Brain repair: cell therapy in stroke. Stem Cells Cloning 7, 31-44. doi: 10.2147/SCCAA.S38003

Kang, S. G., Shinojima, N., Hossain, A., Gumin, J., Yong, R. L., Colman, H., etal. (2010). Isolation and perivascular localization of mesenchymal stem cells from mouse brain. Neurosurgery 67, 711-720. doi 10.1227/01.NEU.0000377859.06219.78

Kern, S., Eichler, H., Stoeve, J., Klueter, H., and Bieback, K. (2006). Comparative analysis of mesenchymal stem cells from bone marrow, umbilical cord blood, or adipose tissue. Stem Cells 24, 1294-1301. doi: 10.1634/stemcells.2005-0342

Kim, J., Ambasudhan, R., and Ding, S. (2012). Direct lineage reprogramming to neural cells. Curr. Opin. Neurobiol 22, 778-784. doi: 10.1016/j.conb.2012.05.001

Kim, S. J., Moon, G. J., Chang, W. H., Kim, Y. H., and Bang, O. Y. (2013). Intravenous transplantation of mesenchymal stem cells preconditioned with early phase stroke serum: current evidence and study protocol for a randomized trial. Trials 14, 317 doi: 10.1186/1745-6215-14-317

Kubis, N., Tomita, Y., Tran-Dinh, A., Planat-Benard, V., Andre, M., Karaszewski, B., et al. (2007). Vascular fate of adipose tissue-derived adult stromal cells in the ischemic murine brain: a combined imaging-histological study. Neuroimage 34, 1-11. doi: 10.1016/j.neuroimage.2006.09.014

Kurozumi, K., Nakamura, K., Tamiya, T., Kawano, Y., Ishii, K., Kobune, M., et al. (2005). Mesenchymal stem cells that produce neurotrophic factors reduce ischemic damage in the rat middle cerebral artery occlusion model. Mol. Ther. 11, 96-104. doi: 10.1016/j.ymthe.2004.09.020

Lalu, M. M., Mcintyre, L., Pugliese, C., Fergusson, D., Winston, B. W., Marshall, J. C., et al. (2012). Safety of cell therapy with mesenchymal stromal cells (SafeCell): a systematic review and meta-analysis of clinical trials. PLoS ONE 7:e47559. doi: 10.1371/journal.pone.0047559

Lancaster, M. A., Renner, M., Martin, C. A., Wenzel, D., Bicknell, L. S., Hurles M. E., et al. (2013). Cerebral organoids model human brain development and microcephaly. Nature 501, 373-379. doi: 10.1038/nature12517

Lee, J. S., Hong, J. M., Moon, G. J., Lee, P. H., Ahn, Y. H., and Bang, O. Y. (2010). A long-term follow-up study of intravenous autologous mesenchymal stem cell transplantation in patients with ischemic stroke. Stem Cells 28, 1099-1106. doi: $10.1002 /$ stem. 430

Leu, S., Lin, Y. C., Yuen, C. M., Yen, C. H., Kao, Y. H., Sun, C. K., et al. (2010) Adipose-derived mesenchymal stem cells markedly attenuate brain infarct size and improve neurological function in rats. J. Transl. Med. 8, 63. doi: 10.1186/14795876-8-63

Li, H., Fan, X., Kovi, R. C., Jo, Y., Moquin, B., Konz, R., et al. (2007). Spontaneous expression of embryonic factors and $\mathrm{p} 53$ point mutations in aged mesenchymal stem cells: a model of age-related tumorigenesis in mice. Cancer Res. 67, 1088910898. doi: 10.1158/0008-5472.can-07-2665

Li, Y., Chen, J., Zhang, C. L., Wang, L., Lu, D., Katakowski, M., et al. (2005). Gliosis and brain remodeling after treatment of stroke in rats with marrow stromal cells. Glia 49, 407-417. doi: 10.1002/glia.20126

Li, Y., Chopp, M., Chen, J., Wang, L., Gautam, S. C., Xu, Y.-X., et al. (2000) Intrastriatal transplantation of bone marrow nonhematopoietic cells improves functional recovery after stroke in adult mice. J. Cereb. Blood Flow Metab. 20, 1311-1319. doi: 10.1097/00004647-200009000-00006

Liu, L., Eckert, M. A., Riazifar, H., Kang, D. K., Agalliu, D., and Zhao, W. (2013). From blood to the brain: can systemically transplanted mesenchymal stem cells cross the blood-brain barrier? Stem Cells Int. 2013, 435093. doi: 10.1155/2013/ 435093

Locatelli, F., Bersano, A., Ballabio, E., Lanfranconi, S., Papadimitriou, D., Strazzer, S., et al. (2009). Stem cell therapy in stroke. Cell. Mol. Life Sci. 66, 757-772. doi $10.1007 / \mathrm{s} 00018-008-8346-1$

Lujan, E., and Wernig, M. (2012). The many roads to Rome: induction of neural precursor cells from fibroblasts. Curr. Opin. Genet. Dev. 22, 517-522. doi: 10.1016/j.gde.2012.07.002

Mahmood, A., Wu, H., Qu, C., Xiong, Y., and Chopp, M. (2013). Effects of treating traumatic brain injury with collagen scaffolds and human bone marrow stromal cells on sprouting of corticospinal tract axons into the denervated side of the spinal cord. J. Neurosurg. 118, 381-389. doi: 10.3171/2012.11.JNS12753

Maltman, D. J., Hardy, S. A., and Przyborski, S. A. (2011). Role of mesenchymal stem cells in neurogenesis and nervous system repair. Neurochem. Int. 59, 347-356. doi: 10.1016/j.neuint.2011.06.008

Meng, X., Su, R. J., Baylink, D. J., Neises, A., Kiroyan, J. B., Lee, W. Y., et al. (2013). Rapid and efficient reprogramming of human fetal and adult blood CD34+ cells into mesenchymal stem cells with a single factor. Cell Res. 23, 658-672. doi: $10.1038 / \mathrm{cr} .2013 .40$

Mitkari, B., Kerkela, E., Nystedt, J., Korhonen, M., Mikkonen, V., Huhtala, T., et al. (2013). Intra-arterial infusion of human bone marrow-derived mesenchymal stem cells results in transient localization in the brain after cerebral ischemia in rats. Exp. Neurol. 239, 158-162. doi: 10.1016/j.expneurol.2012. 09.018

Miyamoto, M., Kuroda, S., Zhao, S., Magota, K., Shichinohe, H., Houkin, K., et al. (2013). Bone marrow stromal cell transplantation enhances recovery of local glucose metabolism after cerebral infarction in rats: a serial 18F-FDG PET study. J. Nucl. Med. 54, 145-150. doi: 10.2967/jnumed.112.109017

Namihira, M., and Nakashima, K. (2011). "Fate specification of neural stem cells," in Neurogenesis in the Adult Brain I, eds T. Seki, K. Sawamoto, J. M. Parent, and A. Alvarez-Buylla (Tokyo: Springer Japan), 87-107. doi: 10.1007/978-4-431-539339_3

Orito, K., Harada, H., Hara, M., Yamashita, S., Kikuchi, K., and Shigemori, M. (2010). Cerebrospinal fluid following cerebral ischemia accelerates the proliferation of bone marrow stromal cells in vitro. Kurume Med. J. 57, 21-28. doi: 10.2739/kurumemedj.57.21

Paul, G., Ozen, I., Christophersen, N. S., Reinbothe, T., Bengzon, J., Visse, E., et al. (2012). The adult human brain harbors multipotent perivascular mesenchymal stem cells. PLoS ONE 7:e35577. doi: 10.1371/journal.pone.0035577

Pham, J. T., and Gallicano, G. I. (2012). Specification of neural cell fate and regulation of neural stem cell proliferation by microRNAs. Am. J. Stem Cells 1 , $182-195$.

Pittenger, M. F., Mackay, A. M., Beck, S. C., Jaiswal, R. K., Douglas, R., Mosca, J. D., et al. (1999). Multilineage potential of adult human mesenchymal stem cells. Science 284, 143-147. doi: 10.1126/science.284.5411.143

Planat-Benard, V., Silvestre, J. S., Cousin, B., Andre, M., Nibbelink, M., Tamarat, R., et al. (2004). Plasticity of human adipose lineage cells toward endothelial cells: physiological and therapeutic perspectives. Circulation 109, 656-663. doi: 10.1161/01.CIR.0000114522.38265.61

Renfranz, P. J., Cunningham, M. G., and Mckay, R. D. (1991). Region-specific differentiation of the hippocampal stem cell line HiB5 upon implantation into the developing mammalian brain. Cell 66, 713-729. doi: 10.1016/00928674(91)90116-G

Rosado-De-Castro, P. H., Pimentel-Coelho, P. M., Da Fonseca, L. M., De Freitas, G. R., and Mendez-Otero, R. (2013a). The rise of cell therapy trials for stroke: review of published and registered studies. Stem Cells Dev. 22, 2095-2111. doi: 10.1089/scd.2013.0089

Rosado-De-Castro, P. H., Schmidt Fda, R., Battistella, V., Lopes De Souza, S. A., Gutfilen, B., Goldenberg, R. C., et al. (2013b). Biodistribution of bone marrow mononuclear cells after intra-arterial or intravenous transplantation in subacute stroke patients. Regen. Med. 8, 145-155. doi: 10.2217/rme.13.2

Safford, K. M., and Rice, H. E. (2005). Stem cell therapy for neurologic disorders: therapeutic potential of adipose-derived stem cells. Curr. Drug Targets 6, 57-62. doi: $10.2174 / 1389450053345028$

Saito, H., Magota, K., Zhao, S., Kubo, N., Kuge, Y., Shichinohe, H., et al. (2013). ${ }^{123}$ I-iomazenil single photon emission computed tomography visualizes recovery of neuronal integrity by bone marrow stromal cell therapy in rat infarct brain. Stroke 44, 2869-2874. doi: 10.1161/STROKEAHA.113.001612

Savitz, S. I., Chopp, M., Deans, R., Carmichael, T., Phinney, D., and Wechsler, L. (2011). Stem cell therapy as an emerging paradigm for stroke (STEPS) II. Stroke 42, 825-829. doi: 10.1161/STROKEAHA.110.601914

Shen, L. H., Li, Y., Chen, J., Zhang, J., Vanguri, P., Borneman, J., et al. (2006). Intracarotid transplantation of bone marrow stromal cells increases axon-myelin remodeling after stroke. Neuroscience 137, 393-399. doi: 10.1016/j.neuroscience.2005.08.092

Shi, Z., and Jiao, J. (2012). Direct lineage conversion: induced neuronal cells and induced neural stem cells. Protein Cell 3, 826-833. doi: 10.1007/s13238-0122068-8

Snyder, E. Y., Deitcher, D. L., Walsh, C., Arnold-Aldea, S., Hartwieg, E. A., and Cepko, C. L. (1992). Multipotent neural cell lines can engraft and participate in development of mouse cerebellum. Cell 68, 33-51. doi: 10.1016/0092-8674(92) 90204-P

Steiner, B., Roch, M., Holtkamp, N., and Kurtz, A. (2012). Systemically administered human bone marrow-derived mesenchymal stem home into peripheral organs but do not induce neuroprotective effects in the MCAo-mouse model 
for cerebral ischemia. Neurosci. Lett. 513, 25-30. doi: 10.1016/j.neulet.2012. 01.078

Suzuki, J., Sasaki, M., Harada, K., Bando, M., Kataoka, Y., Onodera, R., et al. (2013). Bilateral cortical hyperactivity detected by fMRI associates with improved motor function following intravenous infusion of mesenchymal stem cells in a rat stroke model. Brain Res. 1497, 15-22. doi: 10.1016/j.brainres.2012.12.028

Takahashi, K., and Yamanaka, S. (2006). Induction of pluripotent stem cells from mouse embryonic and adult fibroblast cultures by defined factors. Cell 126, 663676. doi: 10.1016/j.cell.2006.07.024

Teng, H., Zhang, Z. G., Wang, L., Zhang, R. L., Zhang, L., Morris, D., et al. (2008). Coupling of angiogenesis and neurogenesis in cultured endothelial cells and neural progenitor cells after stroke. J. Cereb. Blood Flow Metab. 28, 764-771. doi: 10.1038/sj.jcbfm.9600573

Terada, N., Hamazaki, T., Oka, M., Hoki, M., Mastalerz, D. M., Nakano, Y., et al. (2002). Bone marrow cells adopt the phenotype of other cells by spontaneous cell fusion. Nature 416, 542-545. doi: 10.1038/nature730

The STEPS Participants. (2009). Stem Cell Therapies as an Emerging Paradigm in Stroke (STEPS): bridging basic and clinical science for cellular and neurogenic factor therapy in treating stroke. Stroke 40, 510-515. doi: 10.1161/STROKEAHA.108.526863

Ukai, R., Honmou, O., Harada, K., Houkin, K., Hamada, H., and Kocsis, J. D. (2007). Mesenchymal stem cells derived from peripheral blood protects against ischemia. J. Neurotrauma 24, 508-520. doi: 10.1089/neu.2006.0161

Vasconcelos-Dos-Santos, A., Rosado-De-Castro, P. H., Lopes De Souza, S. A., Da Costa Silva, J., Ramos, A. B., Rodriguez De Freitas, G., et al. (2012). Intravenous and intra-arterial administration of bone marrow mononuclear cells after focal cerebral ischemia: is there a difference in biodistribution and efficacy? Stem Cell Res. 9, 1-8. doi: 10.1016/j.scr.2012.02.002

Vierbuchen, T., Ostermeier, A., Pang, Z. P., Kokubu, Y., Sudhof, T. C., and Wernig, M. (2010). Direct conversion of fibroblasts to functional neurons by defined factors. Nature 463, 1035-1041. doi: 10.1038/nature08797

Wan, H., Li, F., Zhu, L., Wang, J., Yang, Z., and Pan, Y. (2013). Update on therapeutic mechanism for bone marrow stromal cells in ischemic stroke. J. Mol. Neurosci. 52, 177-185. doi: 10.1007/s12031-013-0119-0

Wei, L., Fraser, J. L., Lu, Z. Y., Hu, X., and Yu, S. P. (2012). Transplantation of hypoxia preconditioned bone marrow mesenchymal stem cells enhances angiogenesis and neurogenesis after cerebral ischemia in rats. Neurobiol. Dis. 46, 635-645. doi: 10.1016/j.nbd.2012.03.002

Wislet-Gendebien, S., Bruyère, F., Hans, G., Leprince, P., Moonen, G., and Rogister, B. (2004). Nestin-positive mesenchymal stem cells favour the astroglial lineage in neural progenitors and stem cells by releasing active BMP4. BMC Neurosci. 5:33. doi: 10.1186/1471-2202-5-33

Wislet-Gendebien, S., Hans, G., Leprince, P., Rigo, J. M., Moonen, G., and Rogister, B. (2005). Plasticity of cultured mesenchymal stem cells: switch from nestin-positive to excitable neuron-like phenotype. Stem Cells 23, 392-402. doi: 10.1634/stemcells.2004-0149

Wrage, P. C., Tran, T., To, K., Keefer, E. W., Ruhn, K. A., Hong, J., et al. (2008). The neuro-glial properties of adipose-derived adult stromal (ADAS) cells are not regulated by Notch 1 and are not derived from neural crest lineage. PLoS ONE 3:e1453. doi: 10.1371/journal.pone.0001453
Xin, H., Li, Y., Cui, Y., Yang, J. J., Zhang, Z. G., and Chopp, M. (2013). Systemic administration of exosomes released from mesenchymal stromal cells promote functional recovery and neurovascular plasticity after stroke in rats. J. Cereb. Blood Flow Metab. 33, 1711-1715. doi: 10.1038/jcbfm. 2013.152

Yang, N., Ng, Y. H., Pang, Z. P., Sudhof, T. C., and Wernig, M. (2011). Induced neuronal cells: how to make and define a neuron. Cell Stem Cell 9, 517-525. doi: 10.1016/j.stem.2011.11.015

Yang, N., Zuchero, J. B., Ahlenius, H., Marro, S., Ng, Y. H., Vierbuchen, T., et al. (2013). Generation of oligodendroglial cells by direct lineage conversion. Nat. Biotechnol. 31, 434-439. doi: 10.1038/nbt.2564

Yavagal, D. R., Lin, B., Raval, A. P., Garza, P. S., Dong, C., Zhao, W., et al. (2014). Efficacy and dose-dependent safety of intra-arterial delivery of mesenchymal stem cells in a rodent stroke model. PLoS ONE 9:e93735. doi: 10.1371/journal.pone.0093735

Yu, J. M., Bunnell, B. A., and Kang, S. K. (2011). Neural differentiation of human adipose tissue-derived stem cells. Methods Mol. Biol. 702, 219-231. doi: 10.1007/978-1-61737-960-4_16

Yu, Z., Wu, S., Liu, Z., Lin, H., Chen, L., Yuan, X., et al. (2014). Sonic hedgehog and retinoic acid induce bone marrow-derived stem cells to differentiate into glutamatergic neural cells. J. Immunoassay Immunochem. 36, 1-15. doi: 10.1080/15321819.2014.889025

Zhang, Z. G., Zhang, L., Jiang, Q., Zhang, R., Davies, K., Powers, C., et al. (2000). VEGF enhances angiogenesis and promotes blood-brain barrier leakage in the ischemic brain. J. Clin. Invest. 106, 829-838. doi: 10.1172/ jci9369

Zuk, P. (2013). Adipose-derived stem cells in tissue regeneration: a review. ISRN Stem Cells 2013, 35. doi: 10.1155/2013/713959

Zuk, P. A., Zhu, M., Ashjian, P., De Ugarte, D. A., Huang, J. I., Mizuno, H., et al. (2002). Human adipose tissue is a source of multipotent stem cells. Mol. Biol. Cell 13, 4279-4295. doi: 10.1091/mbc.E02-02-0105

Conflict of Interest Statement: The authors declare that the research was conducted in the absence of any commercial or financial relationships that could be construed as a potential conflict of interest.

Received: 31 May 2014; accepted: 24 September 2014; published online: 21 October 2014.

Citation: Ikegame Y, Yamashita K, Nakashima S, Nomura Y, Yonezawa S, Asano Y, Shinoda J, Hara H and Iwama T (2014) Fate of graft cells: what should be clarified for development of mesenchymal stem cell therapy for ischemic stroke? Front. Cell. Neurosci. 8:322. doi: 10.3389/fncel.2014.00322

This article was submitted to the journal Frontiers in Cellular Neuroscience.

Copyright (C) 2014 Ikegame, Yamashita, Nakashima, Nomura, Yonezawa, Asano, Shinoda, Hara and Iwama. This is an open-access article distributed under the terms of the Creative Commons Attribution License (CC BY). The use, distribution or reproduction in other forums is permitted, provided the original author(s) or licensor are credited and that the original publication in this journal is cited, in accordance with accepted academic practice. No use, distribution or reproduction is permitted which does not comply with these terms. 